“C 2019 IEEE. Personal use of this material is permitted. Permission from IEEE must be obtained for all other uses, in any current or future media, including reprinting/republishing this material for advertising or promotional purposes, creating new collective works, for resale or redistribution to servers or lists, or reuse of any copyrighted component of this work in other works." 


\title{
A New Isolated Multi-Port Converter with Multi-Directional Power Flow Capabilities for Smart Electric Vehicle Charging Stations
}

\author{
Shakil Ahamed Khan, Student Member, IEEE, Md. Rabiul Islam, Senior Member, IEEE, \\ Youguang Guo, Senior Member, IEEE, and Jianguo Zhu, Senior Member, IEEE
}

\begin{abstract}
If the batteries are charged by clean renewable energy sources, electric vehicles (EVs) can have zero gas emission, contributing greatly towards the preservation of green environment. In a smart micro-grid, EVs together with other distributed energy storage units can be used to supply electricity to the loads during the peak hours so as to minimize the effects of the load shading and improve the quality of electricity. To achieve these goals, an isolated hybrid multiport converter is required to control the power flows and balance the energy among renewable energy sources, EVs, and the grid. In this paper, a new isolated multi-port converter is proposed, which can control the power flow in multiple directions. Converter is modeled in MATLAB/Simulink environment and this validates the technology with a laboratory prototype test platform. The modeling, implementation, and results are discussed comprehensively.
\end{abstract}

Index Terms-Electric vehicles, battery charger, clean energy, micro-grid, multi-port converter, isolation.

\section{INTRODUCTION}

B ECAUSE the conventional power systems are short of large scale energy storage units, all electricity generated must be consumed by either real or dummy loads. Insufficient generation may lead to load shedding, especially during the peak hours, which significantly increases the electricity price and affects the power grid reliability, whereas excessive generation will lead to waste of energy. Also, the fast consumption of fossil fuels is causing serious problems of energy shortage in developing countries [1]. Recognized as an effective means to resolve these enormous challenges, the smart micro-grids based on renewable energy sources, energy storage units, and electric vehicles (EVs) are becoming more and more popular around the world [2], [3]. If the batteries are charged by clean renewable energy sources, EVs can have zero gas emission, contributing greatly towards the preservation of green environment. In a smart micro-grid, EVs together with other distributed energy storage units can be used to supply electricity to the loads during the peak hours so as to minimize the effects of the load shedding and improve the quality of electricity.

Manuscript submission for review, ............

S. A. Khan and Y. G. Guo are with the School of Electrical and Data Engineering, University of Technology Sydney, 81 Broadway, Ultimo, NSW 2007, Australia. e-mails: Shakil.A.Khan@student.uts.edu.au, Youguang.Guo$1 @$ uts.edu.au.

M. R. Islam is with the School of Electrical, Computer and Telecommunications Engineering, University of Wollongong, NSW 2522, Australia.e-mails: mrislam@uow.edu.au, rabiulbd@hotmail.com.
However, an intelligent hybrid multiport converter is required to control the power flows and balance the energy among renewable energy sources, EVs, and grids [4].

In [5], a motor integrated bidirectional power converter was presented, where a relay was used to change the direction of power flow between EV and the ac or dc grids. Considering the efficiency, the solar photovoltaic (PV) system interfaced dc micro-grid has found its application in interconnecting EVs in parking lot. However, the constant-power operation of dc-dc converter-based EV chargers may affect the stability of the distribution system [4]. Research in [6] focused to develop three-level dc-dc converter-based high-power fast charger for a parking lot to reduce the range anxiety of $\mathrm{EV}$ drivers. Although high-power charger may charge multiple EVs simultaneously, the sudden connection of multiple fast EV chargers may create fluctuations of distribution system voltage and power. High-temperature superconducting (HTS) cables have already proven their superiority in developing emerging power devices to overcome power quality problems [7], [8]. In [9], a superconducting coil was proposed for smoothing the system voltage and power.

A bidirectional buck-boost dc-dc converter with adaptable controller for grid connected EV charging lot was proposed to supply electricity to the loads during the peak hours so as to minimize the effects of the load shedding and improve the quality of electricity [10]. The proposed topology implies multiple power conversion stages, which degrades the conversion efficiency. In [11], a modified Z-source converterbased EV charger has been presented to reduce the power conversion stages. Although the Z-source converter may improve the power conversion efficiency, its operation mostly depends on two capacitors and two inductors. Recently, a common dc-link based three-port converter has been proposed to interface EV, solar PV and the grid with reduced power conversion stages and component counts [12].

However, the galvanic isolation has not been considered in the existing literatures. In this paper, a common magneticlink based multi-port converter is proposed, where the

J. G. Zhu is with the School of Electrical and Information Engineering, The University of Sydney, Sydney, NSW 2006, Australia. e-mail: Jianguo.zhu@sydney.edu.au.

Color versions of one or more of the figures in this paper are available online at http://ieeexplore.ieee.org.

Digital Object Identifier will be inserted here upon acceptance. 
magnetic-link ensures the galvanic isolation. Compared with the existing similar power conversion approaches, the proposed system has the following new features:

- the proposed approach can be extended to $\mathrm{N}$ different $\mathrm{dc}$ buses through a multi-winding transformer to handle a wide variety of dc voltage sources;

- the sources are galvanically isolated, which is an essential requirement for safety purpose in some applications;

- option to accomplish EV battery charging from the energy storages and PV panels during the power outages of the utility grid;

- possibility to store additional energy from the PV module into the energy storage devices; and

- sinusoidal current in the ac side and unity power factor operation for both V2G and G2V operating modes.

\section{OPERAting PrinciPle of THE Proposed CONVERTER}

This section presents detail operation modes of the proposed approach, which combines general multiport dual active bridge $(\mathrm{DAB}) /$ triple active bridge (TAB) converter, bidirectional dcdc converter, and dc-dc unidirectional converter. The circuit diagram of the proposed approach is illustrated in Fig. 1.

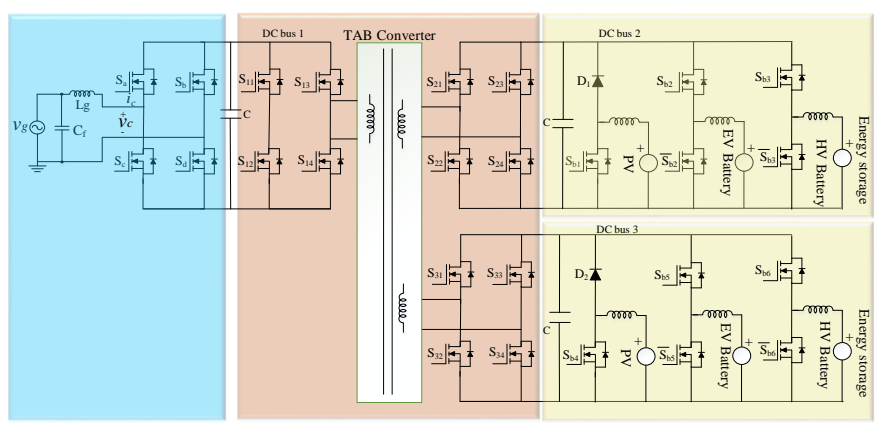

Fig. 1. Circuit diagram of the proposed approach.

In the proposed approach, a bidirectional dc-dc converter is employed to interface the EV battery to provide bidirectional power flow capability with the utility grid and the energy storages. In addition, a conventional dc-dc boost converter is employed to interface the photovoltaic module. The available energy from photovoltaic energy sources can be transferred to EV battery or the energy storage devices. In order to provide bidirectional power flow capability with the utility grid, a bidirectional ac-dc converter is used to generate sinusoidal ac current in the grid side for high-quality power conversion. In this approach, a bidirectional dc-dc converter is used to interface the energy storage devices, which is used to control the charging and discharging operations of the storages. Moreover, the proposed approach can be extended to $\mathrm{N}$ different dc buses through a multi-winding transformer to handle a wide variety of dc voltage sources.

\section{A. Bidirectional ac-dc Converter}

In the proposed approach, the bidirectional ac-dc converter is controlled to generate sinusoidal current in the ac terminal. During the EV charging or energy storage charging modes the converter is controlled to generate the current $\left(i_{c}\right)$ in phase with the grid voltage, and phase opposition during the active power injection into the grid. To realize controlled dc-link voltage, the active power reference is calculated dynamically to regulate the dc-bus voltage. In the proposed system, the grid current reference is calculated from the following expression:

$$
i_{g, r e f}=\frac{2 P_{r e f}}{v_{g d}} \sin (\theta)
$$

where $P_{r e f}$ is the dynamically calculated active power reference value obtained from the proportional integral (PI) controller, $\theta$ is the grid voltage phase angle obtained from the phase-locked loop (PLL), and $v_{g d}$ is obtained from the $\alpha \beta$ to $d q$ conversion. The dynamic model of the converter in the dc-link can be expressed as:

$$
P_{\text {inst. }}=V_{D C .} I_{D C}=V_{D C}\left(i_{C}+i_{L}\right)=C V_{D C} \frac{d V_{D C}}{d t}+V_{D C} i_{L}
$$

where $P_{\text {inst }}$ is the input instantaneous power, $V_{D C}$ represents the dc-link voltage, and $i_{C}$ is the dc-link capacitor current. The employed converter power loss is ignored in this analysis. Therefore, the value of $P_{\text {inst }}$ is equivalent to the active power, which varies proportionally to the dc bus voltage.

The controller output can be defined as:

$$
P_{r e f}=\left(k_{p} e_{d c}+k_{i} \int e_{d c} d t\right) \times V_{D C-\text { link }}
$$

where $e_{d c}$ is the dc-link voltage regulation error.

The voltage regulation error can be expressed as:

$$
e_{d c}=V_{D C-l i n k}-V_{D C-r e f}
$$

where $V_{D C \text {-link }}$ is the bus1 voltage and $V_{D C-r e f}$ is the reference dc-link voltage value.

Similarly, in order to inject the active power into the grid from the PV or energy storage devices, the reference grid current can be calculated from (1).

\section{B. Bidirectional $d c-d c$ Converter}

In the proposed approach, a bidirectional dc-dc converter is considered to transfer power between the energy storage devices and the utility grid. During the EV battery charging or discharging, the converter is controlled to charge or discharge the EV battery with constant current based on the desired value. In the proposed approach, the EV battery charging can be performed by power sharing from the utility grid and the energy storages. In this mode, the grid current reference is calculated from (1) and the rest of the required power is transferred from the energy storage devices. The bidirectional dc-dc converter is controlled to provide constant charging and discharging current. The switches in this converter are operated in the opposite manner in order to avoid a short circuit. When the switching state of the switch Sb1 is 1, the dynamical behavior of the dc-dc converter can be expressed as:

$$
V_{D C-\text { link }}=L \frac{d i_{\text {battery }}}{d t}+V_{\text {battery }}
$$

where $V_{D C \text {-link }}$ is the bus 2 voltage, $L$ the value of the inductance, $V_{\text {battery }}$ the instantaneous value of the battery voltage, and $i_{\text {battery }}$ the instantaneous value of the battery current.

Similarly, when the switching state of the switch Sb1 is 0, the dynamical behavior of the dc-dc converter can be expressed as: 


$$
L \frac{d i_{\text {battery }}}{d t}+V_{\text {battery }}=0
$$

Therefore, the mathematical model of the converter can be represented as:

$$
G . V_{D C-\text { link }}=L \frac{d i_{\text {battery }}}{d t}+V_{\text {battery }}
$$

where $G$ is the switching state. By using the forward Euler method with a sampling period $T_{S}$, (7) can be expressed as:

$$
i_{\text {battery }}^{k+1}=i_{\text {battery }}^{k}+\frac{T_{S}}{L}\left(G . V_{D C \text {-link }}-v_{\text {battery }}\right)
$$

In order to provide constant charging or discharging operation, the cost function can be defined as:

$$
g_{\text {con. }}=\left(i_{\text {battery }}^{k+1}-i_{\text {ref }}\right)^{2}
$$

where $i_{r e f}$ is the desired charging or discharging current.

\section{Unidirectional dc-dc Converter}

A dc-dc boost converter is employed as an interface between the PV module and the dc-link (dc bus 2). In this case, the boost converter is controlled to extract the maximum power from the PV modules by using maximum power point tracking (MPPT) algorithm. In the proposed approach, the energy extracted from the PV module can be stored to the energy storage devices or can be injected into the utility grid. When the PV energy is injected into the grid, the bidirectional converters connected with the energy storage and EV battery are turned off. On the other hand, when the PV energy is used to charge the energy storage, the unidirectional boost converter and the bidirectional converter connected with the energy storage are operated. In this mode, the reference active power from the grid is set to zero. Moreover, during the power outages of the utility grid, the EV battery can be charged directly from the energy available in the PV modules without using the power from the electrical grid.

\section{Performance Evaluation of the Proposed Power CONVERTER}

The interconnection of the EV battery, PV module, energy storages, i.e. high voltage (HV) battery, and the utility grid for the proposed converter is presented in Fig. 1. The interconnection can be accomplished through different operation modes towards successful implementation of the future smart grid concept. The detailed simulation studies have been conducted using MATLAB/Simulink environment to evaluate the performance of the proposed concept with different mode of operations.

\section{A. Grid to Vehicle (G2V) Operational Mode}

In this mode, the power reference value for the energy storage is set to zero. In other words, the bidirectional converter connected with the energy storage is turned off. The full-bridge converter is controlled to generate sinusoidal current in the ac grid side, and the generated current is maintained to be in phase with the grid voltage to have unity power factor operation. Furthermore, the bidirectional dc-dc converter is controlled to charge the EV battery at a constant current rate. Figs. 2(a) and 2(b) show the grid voltage $\left(v_{g}\right)$ and the converter current $\left(i_{c}\right)$, respectively. Clearly, the converter generated current $\left(i_{c}\right)$ is sinusoidal and in phase with the utility voltage $\left(v_{g}\right)$, which demonstrates the unity power factor operation. During this operation mode, the dc-dc bidirectional converter is controlled to charge the EV battery at a constant current (30 A) rate and the energy storage system is disconnected from the system. The wave shapes of the battery state of charge (SOC) and charging current of the EV battery and the energy storage are presented in Figs. 2(c) and 2(d), respectively. It can be observed that the EV battery is charged with the desired current rate, and the energy storage battery SOC is unchanged since the storage is disconnected by the bidirectional converter connected with the storage. Similarly, the energy storage batteries can be charged from the power grid in parallel with the EV charging time by operating the bidirectional converter connected with the energy storage. In this case, the power provided by the utility grid is equal to the EV battery power and the energy storage battery power. The detailed voltage and current wave shapes are presented in Fig. 3.
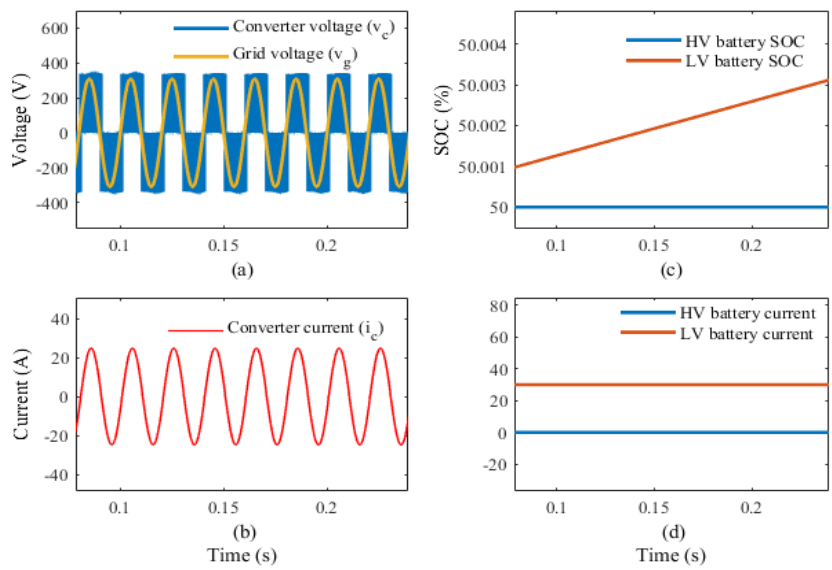

Fig. 2. Grid to EV battery: (a) the grid voltage, (b) the converter current, (c) the battery SOC, and (d) charging current of the EV battery and the energy storage.
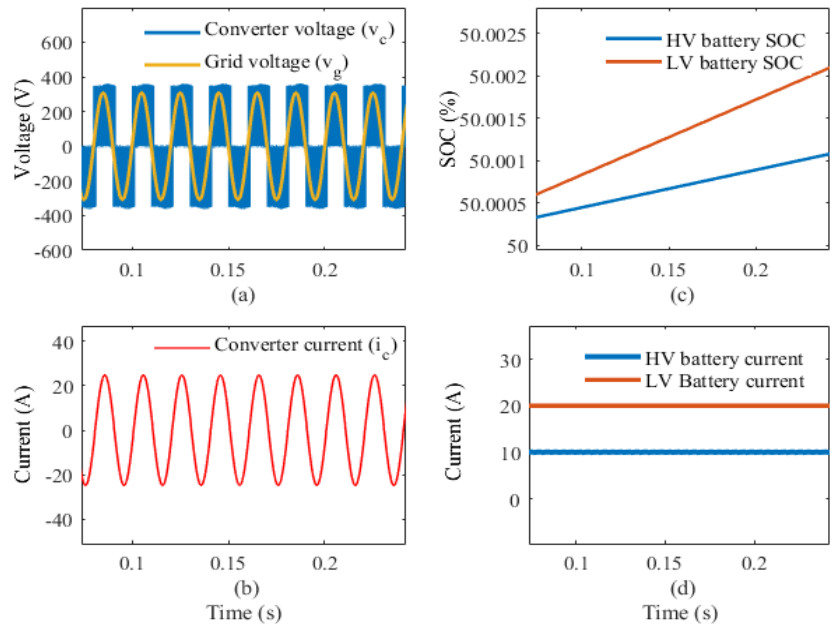

Fig. 3. Grid to EV battery and energy storage: (a) the grid voltage, (b) the converter current, (c) the battery SOC, and (d) charging current of the EV battery and the energy storage.

\section{B. Renewable Energy to Energy Storage (R2Es)}

During this operating mode, the energy available in the PV module is extracted by using an MPPT algorithm through a 
unidirectional $\mathrm{dc}-\mathrm{dc}$ boost converter, and stored in the energy storage devices. In order to have this operation, the bidirectional converter connected with the energy storage is operated to charge it and the reference grid power is set to zero, i.e., the power available in the PV modules is used to the energy storages charging power. Similarly, the EV battery can be charged directly from PV modules by operating the bidirectional dc-dc converter. During this mode, the PV power is equal to the battery power.

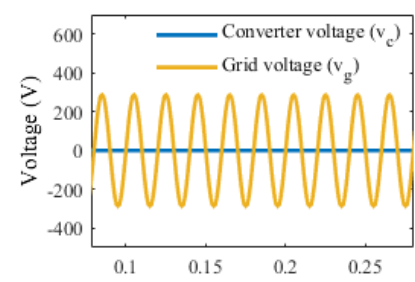

(a)

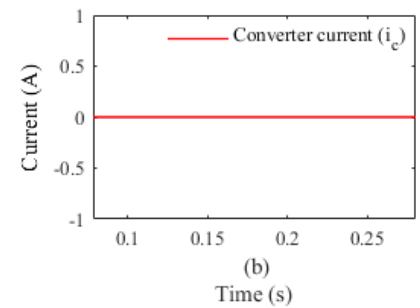

Fig. 4. PV to energy storage: (a) the grid voltage, (b) the converter current, (c) the HV battery SOC, and (d) charging current of the energy storage.
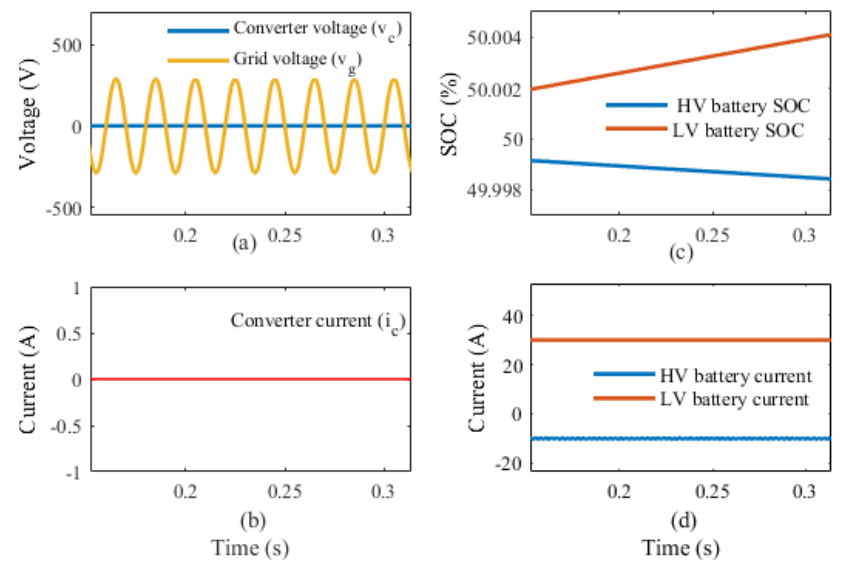

Fig. 5. Energy storage to EV battery: (a) the grid voltage, (b) the converter current, (c) the battery SOC, and (d) charging current of the EV battery and the energy storage.

Fig. 4 shows the power grid voltage $\left(v_{g}\right)$, and the converter generated current $\left(i_{c}\right)$, the energy storage battery current, and the SOC during the R2Es operation mode.

\section{Energy Storage to EV Battery (Es2E)}

In this operating mode, the bidirectional converters connected with both of the EV battery and the energy storage devices are operated to charge the EV battery. During this mode, the grid power is set to zero and the bidirectional dc-dc converter is controlled to charge the EV battery at a constant current rate. When the utility grid outage occurs the energy stored in the energy storage devices can be used to charge the $\mathrm{EV}$ battery, i.e., EV battery power is equal to the energy storages battery power. Figs. 5(a) and 5(b) show the grid voltage $\left(v_{g}\right)$ and the grid current $\left(i_{c}\right)$ wave shapes, respectively for this operating mode. Figs. 5(c) and 5(d) show the EV battery and energy storage battery SOC and charging and discharging current, respectively. As it can be seen that the energy storage battery SOC is decreasing and EV battery SOC is increasing due to the discharging and charging process in this operating mode.

\section{Energy Storage to Grid (E2G) and Renewable Energy to Grid (R2G)}

During these operating modes, the energy available in the energy storage devices and extracted from the PV modules can be injected into the power grid. In these modes, the full-bridge bidirectional converter is controlled to generate sinusoidal ac current in the grid-side, and the generated current is out of phase with the grid voltage, which means that the utility grid receives power from the dc energy sources. To inject power from the energy storage devices the bidirectional converter connected with the energy storage is operated. Fig. 6 shows the utility voltage $\left(v_{g}\right)$ and the grid-side current $\left(i_{c}\right)$ during the power injection from the energy storage. As it can be seen that the generated current is sinusoidal and out of phase with the grid voltage during this operation mode, and the battery SOC is decreasing due to the discharging operation of the battery. Similarly, the power available in the EV battery can be injected into the grid by operating the bidirectional $\mathrm{dc}-\mathrm{dc}$ converter connected with the EV battery. In these cases, the injected power into the grid is equal to the battery power. Moreover, the power extracted from the PV modules can be injected directly into the grid by controlling the dc-dc unidirectional converter. In this case, the energy storage devices are disconnected by turning off the bidirectional converters with the energy storage and EV battery. During this mode, the power extracted from the $\mathrm{PV}$ modules is equal to the injected power into the grid.
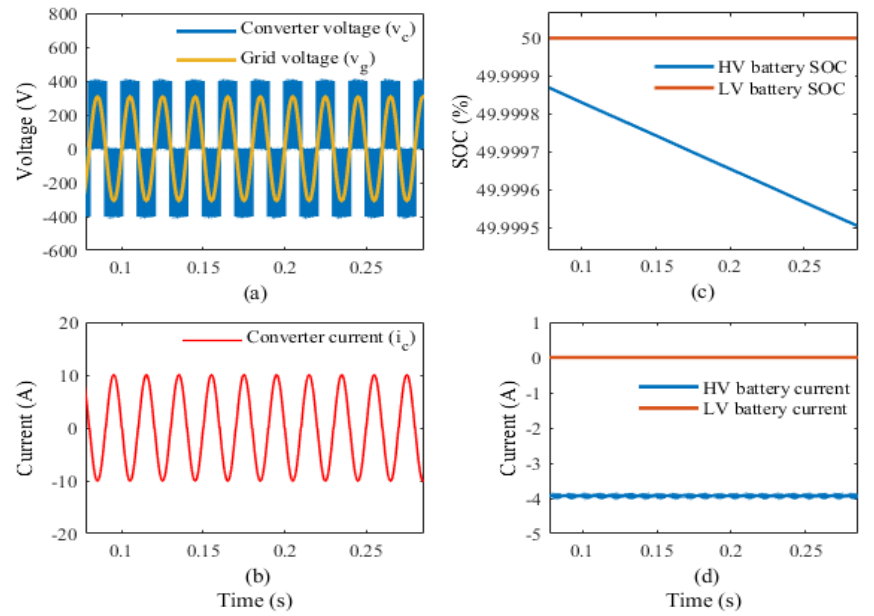

Fig. 6. Energy storage to grid: (a) the grid voltage, (b) the converter current, (c) the battery SOC, and (d) charging current of the EV battery and the energy storage.

Fig. 7 shows the utility voltage $\left(v_{g}\right)$, the grid-side current $\left(i_{c}\right)$, the energy storages SOC and current during this operation mode. As it can be seen that the battery storage SOC is unchanged as the batteries are disconnected from the grid. 


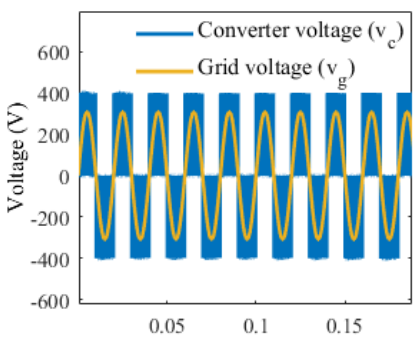

(a)

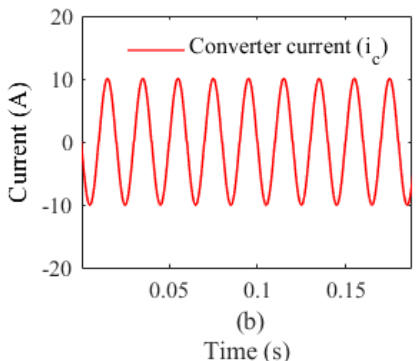

Fig. 7. PV to grid: (a) the grid voltage, (b) the converter current, (c) the battery SOC, and (d) charging current of the EV battery and the energy storage.

In order to demonstrate the capability in realizing the $\mathrm{N}$ different dc buses, the numbers of turns in the secondary windings of the multi-winding transformer are set to different values. The required number of turns depends on the desired bus voltage and the dc voltage gain of the dc-dc converter connected in that particular bus. Fig. 8 shows the simulation results of the dc bus voltage and current waveshapes, where the transformer is designed to have $400 \mathrm{~V}$ in bus 2 and $300 \mathrm{~V}$ in bus 3.

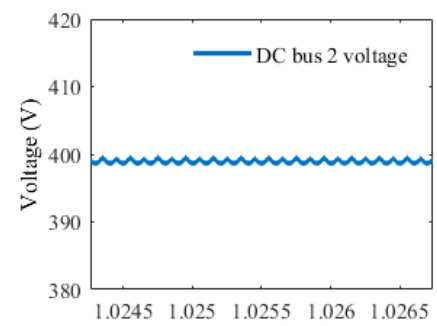

(a)

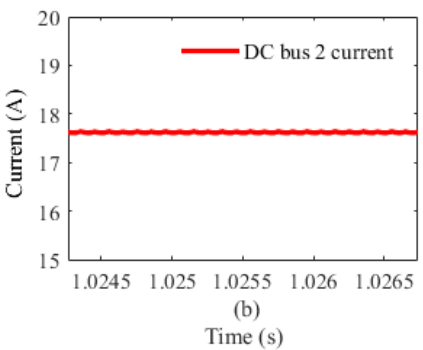

Fig. 8. Simulation results of the dc bus 2 and dc bus 3 voltage and current waveshapes when realizing two different bus voltages.

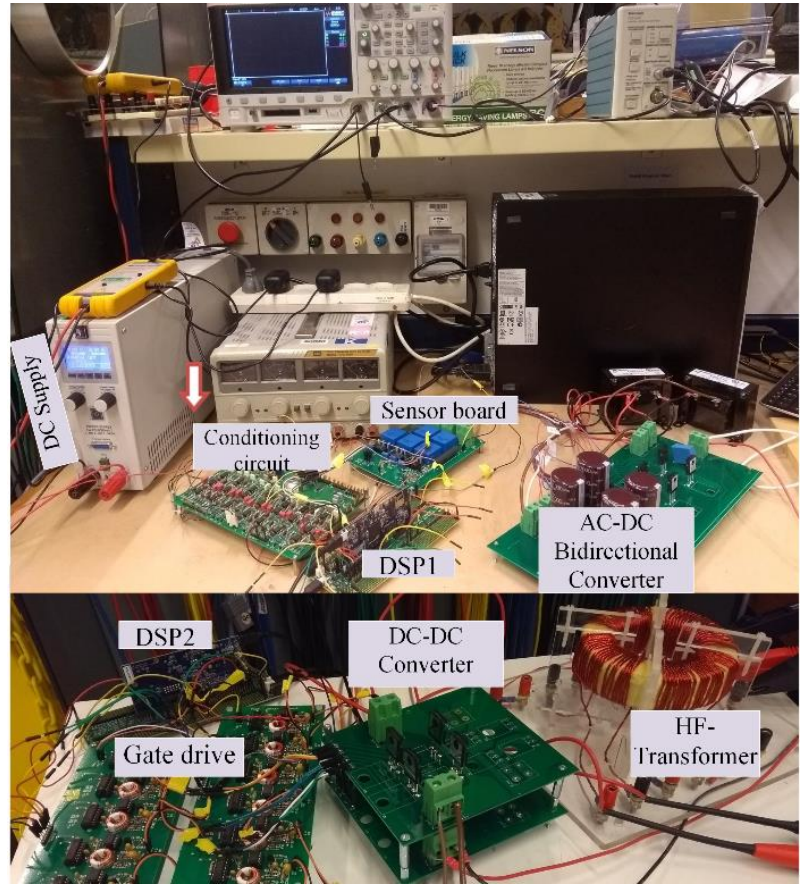

Fig. 9. A photograph of eexperimental test platform.

\section{EXPERIMENTAL VALIDATIONS}

Fig. 9 shows the experimental setup of the proposed system. To accomplish different control tasks two digital signal processor (DSP) microcontrollers (TMS320F28379D) were employed in the proposed system. The different operating modes were defined based on the energy available in the PV systems, grid requirements and the EV operation. A perturb and observe algorithm was implemented to extract the maximum available power from the PV modules. A programmable dc source was used to emulate the PV systems. The energy transfer from energy storages to grid and the grid to energy storage is defined according to the battery storages state of charge and the grid condition. To charge and discharge the energy storages a predictive current strategy was used to control the dc-dc converters, which discussed in the above section. To charge the battery from the grid, the grid current reference is calculated based on the dynamically calculated active power reference value and the grid voltage signal angle calculated by using PLL. In this case, the DAB converter is controlled to transfer power from the primary to the secondary terminal of the highfrequency transformer. Fig. 10 shows the waveforms of the winding 1 current, and the winding 1 and winding 2 voltage waveforms of the high-frequency transformer. Similarly, to transfer power in the opposite direction, the DAB converter is controlled to generate the winding 2 voltage, which is leading the winding 1 voltage. To implement the grid to EV charging mode, an autotransformer is used to step down the grid voltage for the scaled down experimental setup. To observe the grid voltage phase angle, the DSP microcontroller is programmed to generate the output of the PLL. Fig. 11 shows the utility grid voltage $\left(v_{g}\right)$, the output of the PLL, and the converter current $\left(i_{c}\right)$ during the grid to vehicle power transfer mode. It can be observed that the grid voltage and the converter current are in phase, which represents the unity power factor operation. In 
this mode, the dc-dc converter is controlled to generate constant current during EV charging mode.

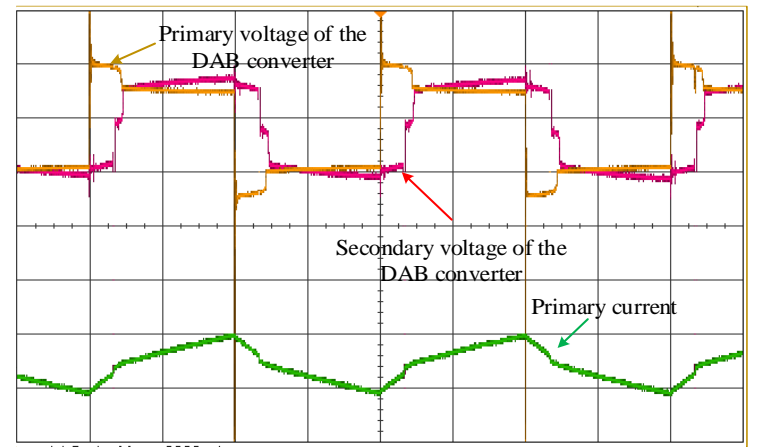

Fig. 10. Measured $\mathrm{DAB}$ converter winding voltages and current waveforms.

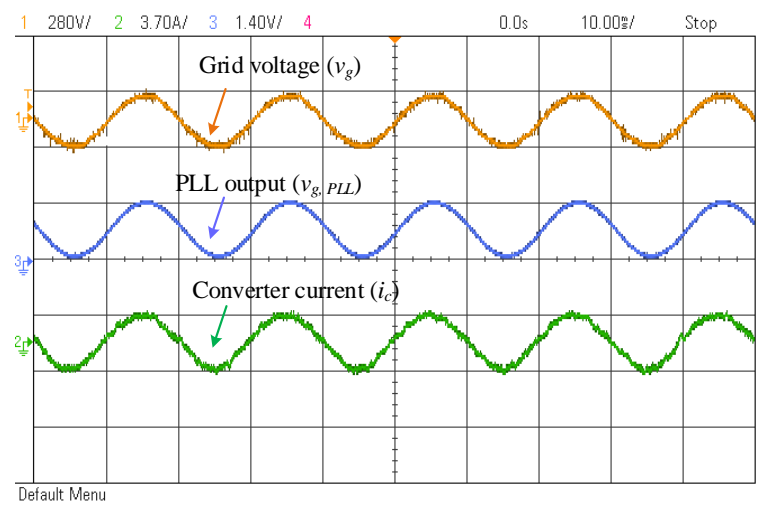

Fig. 11. Experimental results during the grid to vehicle operating mode.

Fig. 12 shows the converter output voltage and the converter output current waveforms. Similarly, during the energy storage to grid power transfer mode, the grid current reference is calculated based on the active power reference value. The dcac bidirectional converter is controlled to generate sinusoidal current to inject power into the grid. Fig. 13 shows the converter output voltage, PLL output voltage, and the converter output current waveforms during this operation mode. During this operation mode, the converter's generated current is in phase opposite to the power grid voltage, which represents the converter is injecting power into the utility grid.

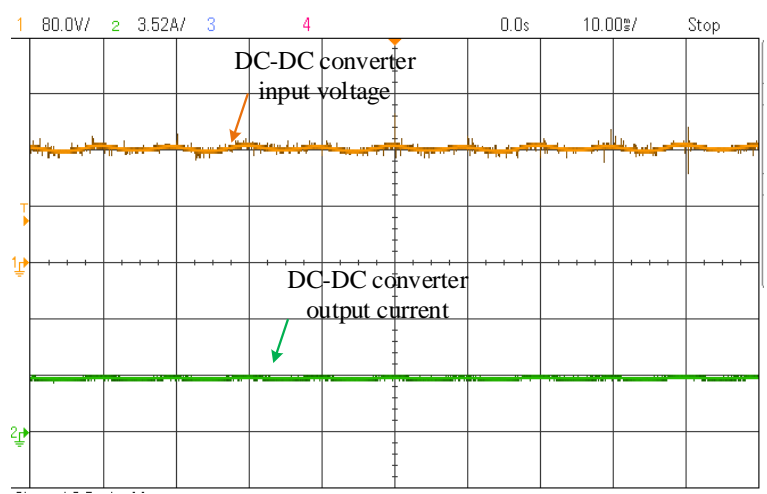

Fig. 12. Measured dc-dc converter input voltage and the output current.

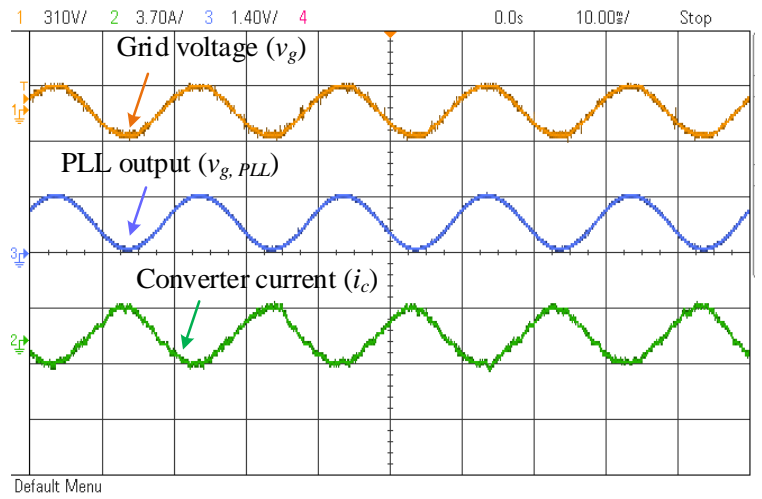

Fig. 13. Experimental results when the active power is injected into the grid from the energy storage system.

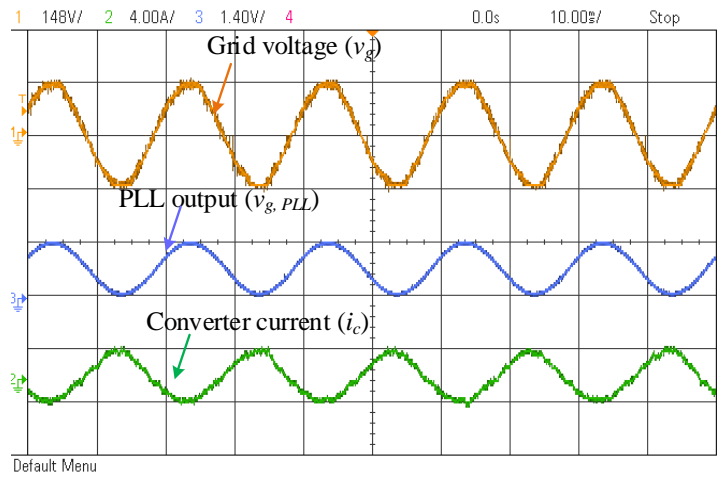

Fig. 14. Experimental results when the active power is injected into the grid from the renewable energy source.

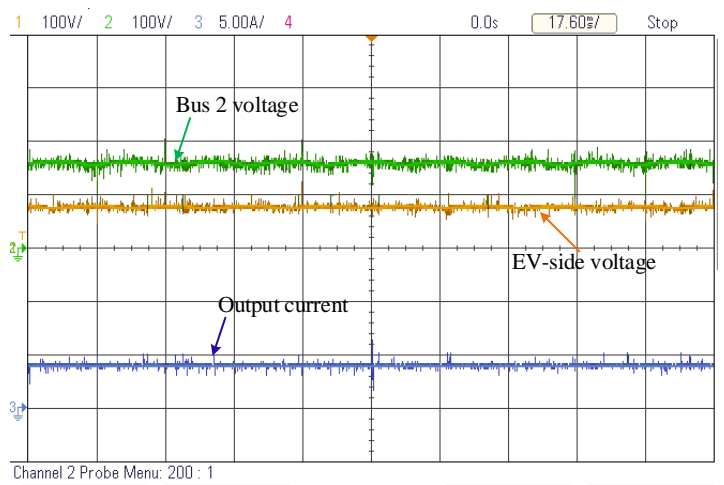

Fig. 15. Experimental results when EV is charged from the energy storage.

To demonstrate the power transfer capability from the $22 \mathrm{G}$, the DSP is programmed for MPPT operation. Fig. 14 shows the utility grid voltage $\left(v_{g}\right)$, the output of the PLL, and the converter generated current $\left(i_{c}\right)$ during the renewable energy source to grid power transfer mode. It can be observed that the converter current is in phase opposite to the power grid voltage, which represents that the converter is injecting power into the utility grid. Experimental studies have been conducted to validate the proposed system to demonstrate the capability to transfer power from the energy storage to EV battery. In this mode, the bidirectional power converters connected with both of the storage and the EV battery are operated to transfer power between these devices. During this operation mode, the power energy storage discharging power is equal to the EV charging power. Fig. 15 shows the waveforms of the bus 2 voltage, EV side voltage and the output current of the dc-dc converter 
connected with the EV battery during the energy storage to EV power transfer mode.

\section{CONCLUSION}

This paper presents a new architecture of an isolated multidirectional power conversion system, which is suitable for smart electric vehicle charging station. This architecture is designed to interface EV battery, energy storage systems, and renewable energy sources to interface with the grid through an isolated system. This approach can be extended to $\mathrm{N}$ different $\mathrm{dc}$ buses through a multi-winding transformer to handle a wide variety of dc voltage sources and provides the necessary isolation to meet the grid standards. The proposed approach has been simulated in MATLAB/Simulink environment and finally validated through the laboratory scale experimental results, which confirms the advantages of the proposed power conversion architecture.

\section{REFERENCES}

[1] L. Xiao, et al., "Development of the world's first HTS power substation," IEEE Trans. Appl. Supercond., vol. 22, no. 3, p. 5000104, Jun. 2012.

[2] B. V. Solanki, et al., "Including smart loads for optimal demand response in integrated energy management systems for isolated microgrids," IEEE Trans. Smart Grid, vol. 8, no. 4, pp. 1739-1748, Jul. 2017.

[3] A. Merabet, et al., "Energy management and control system for laboratory scale microgrid based wind-PV-battery," IEEE Trans. Sust. Ener., vol. 8 , no. 1, pp. 145-154, Jan. 2017.
[4] M. Tabari and A. Yazdani, "Stability of a de distribution system for power system integration of plug-in hybrid electric vehicles," IEEE Trans. Smart Grid, vol. 5, no. 5, pp. 2564-2573, Sept. 2014.

[5] M. A. Khan, I. Husain, and Y. Sozer, "Integrated electric motor drive and power electronics for bidirectional power flow between the electric vehicle and dc or ac grid," IEEE Trans. Power Electron., vol. 28, no. 12, pp. 5774-5783, Dec. 2013.

[6] L. Tan, B. Wu, S. Rivera, and V. Yaramasu, "Comprehensive dc power balance management in high-power three-level dc-dc converter for electric vehicle fast charging," IEEE Trans. Power Electron., vol. 31, no. 1, pp. 89-100, Jan. 2016.

[7] J. X. Jin, et al., "HTS power devices and systems: principles, characteristics, performance, and efficiency," IEEE Trans. Appl. Supercond., vol. 26, no. 7, p. 3800526, Oct. 2016.

[8] Z. Deng et al., "A high-temperature superconducting maglev ring test line developed in Chengdu, China," IEEE Trans. Appl. Supercond., vol. 26, no. 6, p. 3602408, Sept. 2016.

[9] W. Kreeumporn and I. Ngamroo, "Optimal superconducting coil integrated into PV generators for smoothing power and regulating voltage in distribution system with PHEVs," IEEE Trans. Appl. Supercond., vol. 26, no. 7, p. 5402805, Oct. 2016.

[10] N. Saxena, I. Hussain, B. Singh, and A. L. Vyas, "Implementation of a grid-integrated PV-battery system for residential and electrical vehicle applications," IEEE Trans. Ind. Electron., vol. 65, no. 8, pp. 6592-6601, Aug. 2018.

[11] S. A. Singh, G. Carli, N. A. Azeez, and S. S. Williamson, "Modeling, design, control, and implementation of a modified Z-source integrated $\mathrm{PV} / \mathrm{grid} / \mathrm{EV}$ dc charger/inverter," IEEE Trans. Ind. Electron., vol. 65, no. 6, pp. 5213-5220, Jun. 2018.

[12] V. Monteiro, J. G. Pinto, and J. L. Afonso, "Experimental validation of a three-port integrated topology to interface electric vehicles and renewables with the electrical grid," IEEE Trans. Ind. Informat., vol. 14, no. 6, pp. 2364-2374, Jun. 2018. 